\title{
Profiling humoral autoimmune repertoire of dilated cardiomyopathy (DCM) patients and development of a disease-associated protein chip
}

\author{
Sabine Horn ${ }^{1}$, Angelika Lueking ${ }^{2}$, Derek Murphy ${ }^{3}$, Alexander Staudt ${ }^{5}$, \\ Claudia Gutjahr ${ }^{1}$, Kirsten Schulte ${ }^{2}$, Andrea König ${ }^{1}$, Martin Landsberger ${ }^{5}$, \\ Hans Lehrach ${ }^{1}$, Stephan B. Felix ${ }^{5}$ and Dolores J. Cahill'2, 4,6 \\ ${ }^{1}$ Max-Planck-Institute for Molecular Genetics, Berlin, Germany \\ ${ }^{2}$ Medical Proteome Center, Ruhr-University Bochum, Bochum, Germany \\ ${ }^{3}$ Center for Human Proteomics, Royal College of Surgeons in Ireland, Dublin, Ireland \\ ${ }^{4}$ PROTAGEN AG, Dortmund, Germany \\ ${ }^{5}$ AG Molekulare Kardiologie, Klinik für Innere Medizin B, Ernst-Moritz-Arndt-Universität, Greifswald, Germany \\ ${ }^{6}$ Conway Institute of Biomolecular and Biomedical Research, University College Dublin, Ireland
}

Dilated cardiomyopathy (DCM) is a myocardial disease characterized by progressive depression of myocardial contractile function and ventricular dilatation. Thirty percent of DCM patients belong to the inherited genetic form; the rest may be idiopathic, viral, autoimmune, or immune-mediated associated with a viral infection. Disturbances in humoral and cellular immunity have been described in cases of myocarditis and DCM. A number of autoantibodies against cardiac cell proteins have been identified in DCM. In this study, we have profiled the autoantibody repertoire of plasma from DCM patients against a human protein array consisting of 37200 redundant, recombinant human proteins and performed qualitative and quantitative validation of these putative autoantigens on protein microarrays to identify novel putative DCM specific autoantigens. In addition to analyzing the whole IgG autoantibody repertoire, we have also analyzed the IgG3 antibody repertoire in the plasma samples to study the characteristics of IgG3 subclass antibodies. By combining screening of a protein expression library with protein microarray technology, we have detected 26 proteins identified by the IgG antibody repertoire and 6 proteins bound by the IgG3 subclass. Several of these autoantibodies found in plasma of DCM patients, such as the autoantibody against the Kv channel-interacting protein, are associated with heart failure.

\section{Keywords:}

DCM / Dilated cardiomyopathy / Expression library / Protein chip / Protein microarrays
Received: August 26, 2004

Revised: January 12, 2005 Accepted: February 15, 2005

\section{Introduction}

Dilated cardiomyopathy (DCM) is a heart muscle disease characterized by progressive depression of myocardial contractile function and by ventricular dilatation [1]. DCM is a

Correspondence: Professor Dolores J. Cahill, Conway Intitute of Biomolecular and Biomedical Research, University College Dublin, Dublin 4, Ireland

E-mail: dolores.cahill@ucd.ie

Fax: +353-1-402-2453

Abbreviations: DCM, dilated cardiomyopathy; HLA, human leukocyte antigen; KChIPs, $\mathrm{K}^{+}$channel-interacting proteins relevant cause of heart failure and a common indication for heart transplantation. A subgroup of DCM patients belong to the inherited genetic form, the rest may be idiopathic, viral, autoimmune, or immune-mediated associated with a viral infection [1, 2]. Despite recent improvements in therapy, both incidence and mortality of DCM are still high [3]. Recently, evidence has emerged that inflammatory and autoimmune mechanisms play an important role in the pathogenesis of DCM [4, 5]. At least, one-third of DCM patients reveal IgG cardiac-specific antibodies [6]. It has been shown that the injection of blood lymphocytes from DCM patients containing human autoantibodies induces early stage of heart failure in mice [7]. Furthermore, the extraction 
of circulating autoantibodies by immunoadsorption from blood of patients with DCM leads to an improvement in cardiac function indicating an active role of these autoantibodies in the pathogenesis of DCM [8-12]. Apart from simply reflecting an inflammatory response to myocyte necrosis, which would indicate an epiphenomenon or disease markers, such antibodies could initiate the disease process or contribute to the progression of myocardial contractile malfunction.

In particular, autoantibodies against cellular cardiac proteins, like G-protein coupled receptors (e.g., $\beta_{1}$-adrenergic receptors [13, 14]) and muscarinergic receptors (M2), have been identified [15]. In addition, antibodies against membrane components and mitochondrial proteins, especially against the ADP/ATP-carrier protein of the inner mitochondrial membrane, have been associated with the disease [16, 17]. It has been shown that autoantibodies against the ADP/ATP-carrier protein cause a reduction in cardiac function by enhancing the calcium channel current, which leads to calcium overload [18, 19]. Also, autoantibodies against myosin light-chain-1, tropomyosin, HSP-60, and $\alpha$ - and $\beta$-myosin heavy-chain isoforms have been observed [20, 21]. Analysis of IgG subclasses against $\alpha$ - and $\beta$-myosin heavy-chain protein indicated increased levels of IgG3 in DCM patients [22]. Recent data indicate that immunoadsorption removes functionally active negative ionotropic antibodies from the plasma of patients with DCM [23]. These antibodies belong to the IgG subclass 3 [12].

Experimental studies yielded evidence of direct involvement of autoimmunity in the pathogenesis of DCM. Mice deficient in the programmed cell death-1 (PD-1) immunoinhibitory coreceptor develop DCM. Sera of these mice contained high-titer autoantibodies against a heart-specific 30-kDa protein [24]. Recently, this protein was identified as cardiac troponin I [25]. Finally, using an experimental animal model with rats sensitized against the $\beta_{1}$-receptor, direct evidence was demonstrated for $\beta_{1}$-receptor antibodies as a cause of DCM [13].

Autoimmune diseases are characterized by the presence of low- and high-affinity autoantibodies [26]. Although the pathogenic role for most of the autoantibodies in various autoimmune diseases is not clear, the specificity and pathogenicity of the autoimmune response may present an important tool for diagnosis, classification, and prognosis $[27,28]$. Additionally, profiling the autoantibody repertoire may give elucidation into the pathophysiology of autoimmunity, enabling novel treatments such as antigen-tolerising therapy [29, 30]. Protein microarrays have been used for detection and validation of autoantibodies in serum or plasma [31-33].

In this study, we combine protein array technology with the use of large cDNA expression libraries. Büssow et al. [34] have previously shown that cDNA libraries, cloned into an Escherichia coli expression vector, can be screened for protein expression on high-density filter membranes.
Using robot technology [35], a human fetal brain cDNA expression library (hEx1) was picked into microtiter plates and high-density protein arrays were generated on filter membranes followed by in situ protein expression. This approach was extended to automated spotting of protein microarrays from crude lysates of the expression cultures [33]. In an initial analysis of this library, more than $66 \%$ of the clones contain inserts in the correct reading frame. Sixty-four percent of these clones comprise full-length proteins [33]. Furthermore, these expressed proteins are suitable for either MALDI-TOF-MS or functional screening assays [36, 37].

By combining the expression library approach with protein array technology, we have profiled the antibody repertoire in plasma of DCM patients on a human protein array consisting of 37200 redundant, recombinant human proteins, followed by qualitative and quantitative validation of putative autoantigens on protein microarrays.

\section{Materials and methods}

\subsection{Patient data}

Included in this study were patients suffering from DCM (mean age $52.8 \pm 8$ years, NYHA III-IV) and left ventricular dysfunction (left ventricular ejection fraction (LVEF) $<35 \%$; mean $\mathrm{LVEF}=26 \pm 7 \%$; left ventricular internal diameter in diastole $=77 \pm 13 \mathrm{~mm}$ ). Coronary heart disease was excluded by coronary angiography. Patients were excluded if they had a history of arterial hypertension, myocardial infarction, heart failure due to other known origins (e.g., primary valvular disease), or if they had suffered from active infectious diseases, cancer, or chronic alcoholism. From all patients plasma samples were used for screening of cardiac autoantibodies: For control purposes, we used plasma from gender- and age-matched patients (controls). In these patients, coronary heart disease was excluded by coronary angiography which was performed for clinical reasons. Normal left ventricular function was documented by left ventricular angiography.

\subsection{Expression vector and bacterial strain}

An expression subset consisting of 37200 clones of a cDNA library (hEx1) from human fetal brain cloned in the expression vector pQE30NST (GenBank Accession No. AF074376) and transformed into E. coli strain SCS1 (Stratagene) [34] was used for autoantibody profiling.

\subsection{Sequence analysis of expression clones}

cDNA inserts were PCR amplified and tag-sequenced as previously described [36]. The sequences were searched against public databases (NCBI) [38]. 


\subsection{Plasma screening on high-density protein arrays}

High-density protein arrays of the protein expression set of the hEx1 library were obtained from the German Resource Center for Genome Research (RZPD) and prepared as described [34]. For plasma screening, the filters were blocked in 3\% nonfat, dry milk powder in TBST (TBS, $0.1 \% \mathrm{v} / \mathrm{v}$ Tween 20 ) for $2 \mathrm{~h}$, washed twice in TBST and subsequently incubated with plasma diluted $1: 20$ in $2 \% \mathrm{w} / \mathrm{v}$ BSA/TBST for $16 \mathrm{~h}$. After three $30 \mathrm{~min}$ TBST washes and subsequent incubation with the secondary antibody (either mouse-antihuman-IgG, Sigma, or 1:5000 dilution, mouse-antihuman-IgG3, Sigma, 1:400 dilution as appropriate) in $2 \% \mathrm{w} / \mathrm{v} \mathrm{BSA} / \mathrm{TBST}$, the filters were washed three times for $30 \mathrm{~min}$ in TBST. This was followed by incubation with the tertiary antibody (rabbit-antimouse-IgG-AP, Sigma, 1:5000 dilution) in $2 \% \mathrm{w} / \mathrm{v}$ BSA/TBST. Subsequently, the filters were washed three times in TBST-T for $20 \mathrm{~min}$, then for $10 \mathrm{~min}$ in TBS, and then washed for $10 \mathrm{~min}$ in AP buffer $(1 \mathrm{~mm} \mathrm{MgCl}$, $0.1 \mathrm{~m}$ Tris $\mathrm{pH}$ 9.5), followed by incubation in $25 \mathrm{~mm}$ Attophos (JBL Scientific) in AP buffer for $5 \mathrm{~min}$. The filters were illuminated with long-wave UV light and the images were taken using a high-resolution CCD detection system (Fuji). Image analysis was done using VisualGrid.

\subsection{Protein expression and purification in high throughput}

Each protein was expressed twice in $1 \mathrm{~mL}$ cultures in deepwell microtiter plates. The protein extracts of each culture were generated as described [39] and combined. Proteins were purified as previously described [36].

\subsection{Generation of protein microarrays}

The FASTslides (Schleicher \& Schuell) were placed in a Q-Array System (Genetix, New Milton, UK), equipped with humidity control (65\%) and 16 or 24 blunt-ended stainless steel print tips with a tip diameter of $150 \mu \mathrm{m}$. All protein antigens were spotted in three different concentrations (undiluted, 1:2, and 1:5 diluted). For most of the proteins, spotting of the undiluted purified proteins leads to immobilization of $15 \mathrm{fmol}$ protein per spot on the microarray (undiluted: $15 \mathrm{fmol}$; 1:2: $8 \mathrm{fmol}$; 1:5: $3 \mathrm{fmol}$, respectively). Each protein microarray includes several control spots, e.g., human or mouse IgG antibody in three concentrations (human IgG: 1:1000, 1:2500, and 1:5000; mouse-antihuman-IgG: 1:1000, 1:2500, and 1:5000; mouse-antihuman-IgG3: $1: 500,1: 1000$, and 1:2500) as well as a control protein, human myosin (undiluted, 1:2, and 1:5 diluted) which is a common naturally occurring autoantigen.

For the so-called IgG protein chip a $6 \times 6$ spot pattern was printed onto the slides, including all proteins, antibodies and controls and their dilution as duplicates. For the so-called IgG 3 protein chip a $5 \times 5$ spot pattern was printed onto the slides, where each protein and its dilutions were present four times. In all cases, each spot was loaded once transferring $2 \mathrm{~nL}$ per spot.

\subsection{Plasma screening on protein microarrays}

After spotting, the protein chips were blocked in $2 \% \mathrm{w} / \mathrm{v}$ BSA (BSA/TBST, $0.1 \% \mathrm{v} / \mathrm{v}$ Tween 20) at room temperature and the plasmas were added diluted either 1:100 (IgG) or 1:50 (IgG3), as appropriate, in $2 \% \mathrm{w} / \mathrm{v}$ BSA/TBST. The protein chips were incubated in a humidified atmosphere for $16 \mathrm{~h}$ at $4^{\circ} \mathrm{C}$. Following three 30 -min TBST washes and subsequent incubation with the secondary antibody (mouseantihuman-IgG, Sigma, 1:5000 dilution, mouse-antihumanIgG3, Sigma, 1:400) in 2\% w/v BSA/TBST, the protein chips were washed three times for $20 \mathrm{~min}$ in TBST. This was followed by incubation with the tertiary antibody (rabbit-antimouse-IgG-Cy3 or rabbit-antimouse-IgG-Cy5, Dianova, $1: 800$ dilution) in $2 \% \mathrm{w} / \mathrm{v}$ BSA/TBST. Subsequently, the chips were washed three times, each in TBST for $20 \mathrm{~min}$. All secondary and tertiary antibody incubation steps were performed for $1 \mathrm{~h}$ at room temperature and carried out in a 200$\mu \mathrm{L}$ volume underneath a cover slide in the dark. These protein chips were imaged using a confocal microarray reader (ScanArray 4000, Perkin Elmer Life Science).

\subsection{Bioinformatic analysis}

Image analysis was performed using GenePix Pro 3.0 (Axon) or ScanArray Express (Perkin Elmer Life Science), and the mean intensity (median background subtracted) was determined for each protein feature. The average value of the protein duplicates or quadruplicates was calculated (average $_{\text {protein }}$ of patient plasma $_{n}$ or control plasma ${ }_{n}$ value) followed by the determination of the quality of the screen by calculating the $\mathrm{CV}$ of the control proteins human IgG and mouse IgG, respectively. These values were also used for interchip normalization. Each chip was normalized against the $\mathrm{RGSHis}_{6}$ epitope tag intensity, which reflects the appropriate protein concentration. The mean of all average intensities for each protein spotted and its associated dilutions of each control plasma (named: average protein $_{\text {of control plasma }}$ value) was calculated. In the following, this is called the

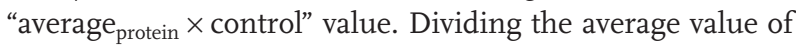
each individual patient plasma (named: average $_{\text {protein }} \times$ patient plasma $_{n}$ value) by the "average protein $\times$ control value" results in the so-called factor $F$, and for this analysis we suggested $F$ values above 2 were significant for the disease.

\section{Results and discussion}

\subsection{Profiling the antibody repertoire against a human protein array containing 37200 redundant proteins}

Screening protein arrays with body fluids, such as serum or plasma from large numbers of patients with an autoimmune disease, for example rheumatoid arthritis, diabetes, multiple 
sclerosis, or alopecia would not only allow the identification of potentially novel autoantigens, but also potentially assist the prognosis, diagnosis, and subtyping of autoimmune diseases based on the presence of specific autoantibodies [40]. In this study, we used a human high-density protein array containing 37200 redundant, recombinant proteins derived from a human fetal brain expression library. The use of such a cDNA expression library eliminates the need to construct individual expression clones for every protein of interest. By introducing a sequence coding for an affinity tag (e.g., Histidine tag, GST tag) to the 5' end of the cDNA insert, resulting expression clones can be rapidly identified by the presence of the His- or GST-tagged fusion protein. E. coli is most commonly used in automated recombinant expression and purification as it is a robust and convenient host organism [36, $41,42]$. It has to be considered that many eukaryotic proteins end up in cytoplasmic inclusion bodies when they are expressed in E. coli and can only be recovered in the denatured state. However, it has been recently demonstrated by Robinson et al. [32] and Quintana et al. [28] that serum screening against peptides leads to reasonable results, showing that antibodies in serum can recognize linear epitopes. Therefore, the human high-density protein array containing 37200 human proteins is an important high-content protein resource.

These high-density protein arrays were incubated with plasma from ten patients with DCM. The antibody repertoire in plasma was detected using antihuman-IgG antibody (Fig. 1A). Taking into account the characteristics of IgG3 antibodies in DCM patients $[11,22]$, the IgG3 antibody repertoire in plasma was also analyzed using antihumanIgG3 secondary antibody.

A high reproducibility of over $80 \%$ was determined when separate, independent incubations using the same patient plasma were performed against two separate human protein arrays (Fig. 1B). The data sets obtained from ten DCM patient plasma screenings were compared to ten age- and sex-matched control plasmas from persons without heart

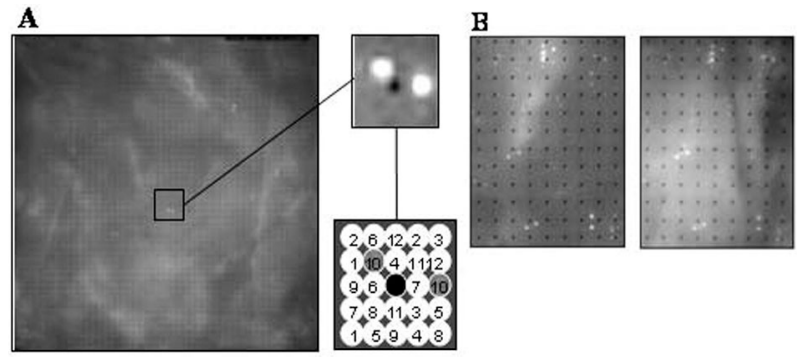

Figure 1. Plasma screening on high-density protein arrays. (A) A high-density protein array of the human fetal brain library was incubated with plasma of a DCM patient. IgG3-specific antibodies were detected using an antihuman-lgG3 secondary antibody. Positive clones were identified using the $5 \times 5$ pattern (left panel). (B) Reproducibility of two different high-density protein arrays incubated with the same patient plasma. A reproducibility of over $80 \%$ was determined. diseases, and to background incubations with antihumanIgG and antihuman-IgG3. We postulate that autoimmune diseases are correlated with a specific autoimmune response leading to a specific autoantibody profile. When comparing the control and DCM results, we found that all proteins that were recognized by antibodies in two or more control plasmas were also seen in DCM patient plasma, i.e., in this study we did not find a healthy, control-associated profile. In contrast, we identified a large number of protein antigens in plasma from both DCM patients and controls, the natural autoantibody (NAA) profile. IgG antibodies against cytoskeletal proteins such as tubulin, its interacting protein stathmin, and myosin were found in $80 \%$ of all samples (disease and controls). The presence of such natural autoantibodies is well recognized and they have been found in all individuals $[43,44]$. We determined such NAAs to ascertain the quality of the used plasma. Here, we used skeletal myosin as a marker to monitor the plasma quality and identified $88 \%$ of the plasma samples in this study. This confirms other recent findings [45].

From these data, proteins exclusively detected by antibodies in DCM patient plasma were determined. When we considered proteins, which were detected by antibodies in two or more of the ten DCM patients, but were not recognized by plasma from the ten controls, we identified two subsets deriving from the IgG (48 proteins) and IgG3 (32 proteins) antibody profiling experiments. 5'-tag sequencing of these clones was performed and their sequences were used for BLAST searches against the public databases including GenBank and UniGene [38].

Since the proteins on the high-density protein arrays have not been immobilized in a purified state, this may result in unspecific cross-reactions or higher S/Ns. Consequently, we further characterized these putative DCM specific protein subsets by using highly sensitive protein microarrays comprising purified proteins. In addition to their much higher sensitivity, protein microarrays require very small amounts of samples and enable a higher throughput due to their small size, when compared with the larger highdensity protein arrays. Therefore, we used the protein microarrays for qualitative and quantitative validation of the putative autoantigens using a larger patient and control plasma collection.

\subsection{Qualitative and quantitative validation of putative autoantigens on protein microarrays}

The recombinant proteins selected above were expressed from the bacterial clones and purified, in parallel, under denaturing conditions. This corresponds to the state of the proteins immobilized on the PVDF protein array. Following high-throughput protein expression and purification, three concentrations of these recombinant purified proteins were generated, namely undiluted, 1:2, and 1:5 dilution. For most of the proteins, spotting of the undiluted protein leads to immobilization of $15 \mathrm{fmol}$ of protein per spot on the micro- 
array (undiluted, $\sim 15$ fmol, 1:2 $\sim 8$ fmol, 1:5: $\sim 3$ fmol, respectively). Each protein sample was spotted in duplicate, onto three fields of a microscope glass slide coated with a 3-D NC-based matrix, using a transfer stamp consisting of 16 pins with a $150 \mu \mathrm{m}$ tip size. Each set of proteins derived from the IgG and IgG3 antibody profiling experiments were immobilized onto a single chip leading to a so-called DCMIgG or DCM-IgG3 protein microarray. To enable inter- and intrachip image analysis, as well as process controlling, human IgG (in the form of human plasma) and mouse IgG (in the form of mouse-antihuman-IgG/IgG3) were included in different dilutions (human IgG: 1:1000, 1:2500, and 1:5000 dilutions; mouse IgG: 1:1000, 1:2500, and 1:5000 dilutions; IgG3: 1:500, 1:1000, and 1:2500 dilutions). Skeletal myosin protein was also included as a positive control in the IgG chip as most of the plasma samples contain IgG antibodies against this protein. It has been shown that $90-95 \%$ of individuals have natural autoantibodies against skeletal myosin [45]. The DCM-IgG and DCM-IgG3 protein microarrays were incubated with 56 DCM patient plasmas, which include the original ten DCM patient plasmas used in the initial protein PVDF array screening. In addition, 30 corresponding ageand sex-matching healthy control plasmas were also screened, these included the original ten control plasmas used in the first screening of the protein PVDF arrays (Fig. 2). Additionally, a protein microarray from each spotted chip batch was incubated with an antiRGSHis ${ }_{6}$ antibody directed against the amino-terminal $\mathrm{RGSHis}_{6}$ tag of the immobilized recombinant protein. The resulting intensities, which reflect the corresponding protein concentration, were used for normalization (by dividing each intensity value from the plasma incubation by the corresponding $\mathrm{RGSHis}_{6}$ intensity value). To analyze the quality of the plasmas, the average intensity of the control protein, myosin, was determined for the patient and control plasma groups. A low

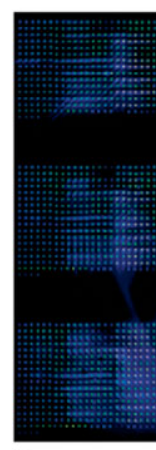

$\mathbf{A}$

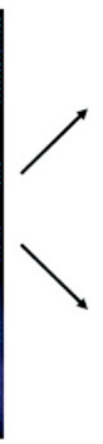

$\mathbf{C}$
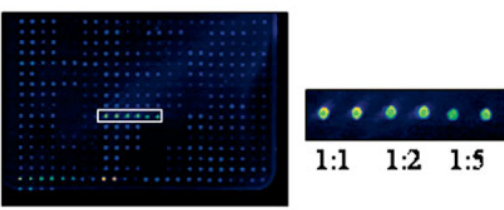

$\begin{array}{lll}1: 1 & 1: 2 & 1: 5\end{array}$ B
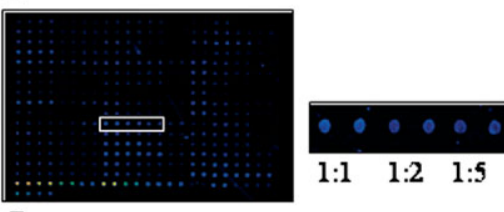

$1: 1 \quad 1: 2 \quad 1: 5$
Figure 2. DCM-lgG microarray consisting of 48 putative DCM associated proteins and several control proteins spotted onto three identical fields on a coated glass slide. (A) DCM-IgG microarray incubated with an antibody directed against the $\mathrm{RGSHis}_{6}$ epitope. (B) Incubation of the DCM-IgG microarray with a patient plasma sample (middle field) and an enlarged extension of differentially detected proteins when compared to a sex- and agematched control plasma sample (C).
SD was observed, resulting in a CV of 5-25\%. This indicates a comparable quality of the patient and control plasma. The intensities of six plasmas of the patient group (13\%) and three plasmas of the control group (10\%) were below background. Therefore, more than $88 \%$ of the plasmas show natural autoantibodies against this type of myosin confirming previously presented data [45].

To analyze the quality of the plasma screening, the CVs of the process control antigens, namely human IgG and mouse IgG/IgG3, were determined for each incubated microarray and the average $\mathrm{CV}$ was then calculated. The analysis of the IgG screening shows an average CV of mouse $\operatorname{IgG}$ of $46 \%$ and of mouse IgG3 of $35 \%$. For further analysis, for each group, i.e., the control plasma group and the patient plasma group, respectively, an average signal intensity of the control proteins was determined. Here, we observed that nearly all intensities of the control proteins were lower in the control plasma group by a factor of 0.7 . Consequently, we applied this factor to the intensity values of all proteins of the patient plasma group.

The IgG3 screening revealed an average CV for human IgG3 of $27 \%$ and of mouse IgG of $32 \%$. These results reflect a good quality for the IgG3 screening.

Following bioinformatic analysis of these results, significant differences between patient and control plasmas have been determined for 10 proteins in all dilutions and 16 proteins in the 1:5 dilution on the DCM-IgG. Six proteins which were predominantly detected by patient plasmas have been identified on the DCM-IgG3 protein microarray (Table 1). Some of the putative DCM associated protein autoantigens showed higher $F$ values when the diluted plasma was used.

The pathophysiological role of the proteins identified here will need to be determined in future studies.

\subsection{Remarks on putative autoantigens}

Natural autoantibodies against cytoskeletal proteins such as tubulin, its interacting protein stathmin, and myosin were found in over $80 \%$ of diseased and control samples.

We have not identified any known DCM markers such as the $\beta$-receptor [13]. Based on sequence analysis of approximately 8000 clones of the nonredundant Uniclone set [46, 47], the conclusion is justified that the library does not contain such known DCM markers. Basically, we detected proteins with no clear pathophysiological role, so that the importance of each of the proteins identified has to be detected in further studies.

Previous research has investigated the function of some of the proteins identified by our protein array technology. Speculation is provided that these proteins also play a role in cardiac function and hence may be involved in cardiovascular diseases. However, it is important to point out that a potential role in DCM must be investigated by further studies. Below, we discuss the role of some of the identified proteins $(\mathrm{a}-\mathrm{h})$. 
Table 1. Protein antigens detected by plasma from DCM patients and their cellular location or function

Protein antigens identified and their cell location or function

Cell surface protein

Low density lipoprotein-related protein associated protein 1 (LRPAP1)

Plasma/sarcolemmal/peroxisomal membrane associated

Choline kinase-like (CHKL), transcript variant 2

Kv channel-interacting protein 1 (KCNIP1)

Peroxisome biogenesis factor 13 (PEX13)

PAP-2-like protein 2 (PHP2)

Nuclear

Neural proliferation, differentiation, and control, 1 (NPDC1)

PCF11p homolog (PCF11)

CDC37 cell division cycle 37 homolog (Saccharomyces cerevisiae) (CDC37)

Similar to CGI-30 protein, clone IMAGE:5189198

RNA binding motif protein 6 (RBM6)

Neurogenic differentiation 2 (NEUROD2)

Nuclease sensitive element binding protein 1 (NSEP1)

Zinc finger protein 142 (ZNF142)

BAC clone RP11-367J11 from 4

Similar to Rec8p, a meiotic recombinant and sister chromatid cohesion phosphoprotein of the rad21p family

Immunosystem-mediated

HLA class II associated protein I

Rapamycin binding protein (FK506)

Cytoplasma

Tubulin, alpha 3

Mitochondria/endoplasmatic reticulum

NDRG family member 4 (NDRG4)

Proteasome

Ubiquitin-specific protease 47 (USP47)

NAC alpha mRNA

Heat shock 70 kDa protein 4 (HSPA4)

Unknown

Chromosome 7 clone RP11-309L24

Chromosome 7 clone RP11-148L5

Clone IMAGE:4540326

FLJ00116 protein

cDNA DKFZp667L0421

Hypothetical protein MGC15730

BAC clone RP11-367J11 from 4

Sequence from clone RP11-342C24 on chromosome 10

Hypothetical protein FLJ20203

cDNA DKFZp761F069 (from clone DKFZp761F069)

BAC clone RP11-535F1 from 7

By lgG/lgG3 Accession no.
specific

\begin{tabular}{|c|c|c|c|c|}
\hline & & \\
\hline & & Undiluted & $1: 2$ & $1: 5$ \\
\hline $\lg G$ & NM_002337 & 46 & 59 & 61 \\
\hline $\lg G 3$ & NG_003100 & 14 & 50 & 16 \\
\hline $\lg G$ & NM_014592 & 23 & 50 & 50 \\
\hline $\lg G$ & NM_002618 & 48 & 52 & 63 \\
\hline $\lg G$ & AF357888 & & & 78 \\
\hline $\lg G$ & NM_015392 & 52 & 54 & 61 \\
\hline $\lg G$ & CD579726 & 48 & 63 & 63 \\
\hline $\lg G$ & NM_007065 & 30 & 54 & 52 \\
\hline $\lg G$ & AU099517 & & & 67 \\
\hline $\lg G$ & NM_005777 & & & 57 \\
\hline $\lg G$ & NM_006160 & & & 54 \\
\hline $\lg G$ & XM_059214 & & & 61 \\
\hline $\lg G$ & NM_005081 & & & 63 \\
\hline $\lg G$ & AC097382 & & & 52 \\
\hline $\lg G$ & BC010887 & & & 50 \\
\hline
\end{tabular}

\begin{tabular}{|c|c|c|c|c|}
\hline $\lg G$ & & & & 82 \\
\hline $\lg G$ & M96256 & & & 54 \\
\hline $\lg G 3$ & BC050637 & 56 & 20 & 22 \\
\hline $\lg G 3$ & NM_022910 & 52 & 34 & 10 \\
\hline $\lg G$ & BC047044 & 44 & 50 & 63 \\
\hline $\lg G$ & AY034001 & 41 & 50 & 63 \\
\hline $\lg G$ & XM_114482 & & & 70 \\
\hline $\lg G$ & AC025594 & 55 & 58 & 78 \\
\hline $\lg G$ & AC083868 & 59 & 63 & 70 \\
\hline $\lg G 3$ & BC044933 & 40 & 50 & 58 \\
\hline $\lg \mathrm{Ig} 3$ & AK024506 & 26 & 52 & 40 \\
\hline $\lg G 3$ & AL833672 & 44 & 56 & 24 \\
\hline $\lg G$ & NM_032880 & & & 63 \\
\hline $\lg G$ & AC097382 & & & 52 \\
\hline $\lg G$ & AL603982 & & & 59 \\
\hline $\lg G$ & NM_017710 & & & 57 \\
\hline $\lg G$ & AL136596 & & & 52 \\
\hline $\lg G$ & AC073422 & & & 67 \\
\hline
\end{tabular}

(a) For example, the gene coding for LRPAP1 has been shown to contain a silent polymorphism among females with coronary artery disease [48] and an additional variation in intron 1 of the LRPAP1 gene could contribute to the risk of developing myocardial infarction [49].

(b) NPDC1 is primarily expressed in the brain and also relatively high in heart, but is hardly detectable in thymus, peripheral blood leukocytes, and colon [50]. It has been shown that NPDC1 down-regulates cell proliferation and interacts in vitro with the transcription factor E2F-1 and some cell cycle proteins, such as D-cyclins and cdk2. It is interesting that the identified CDC37 protein antigen (Table 1), which regulates the T-cell proliferation, interacts also with cyclin D. In mammalian two-hybrid experiments, it was demonstrated that the interaction between NDPC1 and E2F-1 reduces the binding of E2F-1 to DNA and its tran- 
scriptional activity, suggesting that NPDC-1 could influence cell cycle progression and neural differentiation through its association with E2F-1 [51, 52].

(c) The related PAP2 has been shown to be inhibited by $\mathrm{Mg}^{2+}$ and was localized to the sarcolemmal membrane [53]. PAP2 was considered an important enzyme, as it has been shown to modulate the sarcolemmal levels of phosphatidic acid and 1,2 diacylglycerol [54]. The importance of phosphatidic acid in heart function is evident from its ability to stimulate sarcolemmal $\mathrm{Ca}^{2+}$-related transport systems, and 1,2 diacylglycerol has been shown to activate PKC isozymes which phosphorylate several myocardial proteins including ion channels [55]. This may be important in relation to DCM, where a change in intracellular $\mathrm{Ca}^{2+}$ homeostase has also been observed [56, 57].

(d) Mammalian voltage-gated potassium $\mathrm{K}^{+}$channels are assemblies of pore-forming $\alpha$-subunits and modulating $\beta$ subunits. Kv4 $\alpha$-subunits in the heart and CNS require recently identified $\beta$-subunits of the neuronal calcium sensing protein family called $\mathrm{K}^{+}$channel-interacting proteins (KChIPs). KChIP1 belongs to four Kv channel-interacting proteins, and KChIP1, 3, and 4 are predominantly expressed in brain whereas KChIP2 is predominantly in heart [58]. Sequence comparison between the identified brain-specific protein KChIP1 and the heart-specific KChIP2 shows a homologous region of about 107 aminoacids with a homology of $71 \%$ in this region, suggesting potentially a common epitope or epitopes were recognized (Fig. 3). It has been shown that KChIP2 (-/-) knock-out mice were highly susceptible to cardiac arrhythmias and were characterized by a complete absence of transient outward potassium current [59].

(e) As can be seen in Table 1, we identified tubulin $\alpha$ using antihuman-IgG3 secondary antibodies. Tubulin $\alpha$ acts as a subunit of the microtubuli, which are important for cell structure, the intracellular transporting system, and cell division [60]. Tubulin is already known to be an autoantigen in other autoimmune diseases, such as systemic lupus erythematosus [61]. Antibodies against tubulin have also previously been identified in the plasma of healthy individuals $[45,62]$. However, in this study we have identified tubulin as a putative IgG3-specific autoantigen in DCM patients.

(f) NDRG4 was detected with the antihuman-IgG3 antibody (Table 1) and is expressed in brain and heart [63]. NDRG4 was shown to be involved in the regulation of mitogenic signaling in vascular smooth muscle cells [64].

(g) We also identified proteins that may be more involved in the immune system, such as the rapamycin binding protein (FK506) and human leukocyte antigen (HLA) class II associated protein 1. FK506 was described as an immunosuppressive drug, mediating an inhibition of the calcium- activated phosphatase calcineurin [65]. Previously, it has been reported that activated splenic $\mathrm{T}$ lymphocytes deficient in FK506 binding protein 12 have reduced proliferation in response to IL15 [66]. HLA class II alleles have been found to be associated to type 1 diabetes mellitus [67].

(h) Other proteins we have identified in this study are involved in essential components in different biological process, but there is no direct connection to heart failure or to the immune system. For example, PEX13 is a peroxisomal integral membrane protein and an essential component of the peroxisomal protein transport machinery. Mutations in the gene coding for PEX13 lead to peroxisomal metabolic dysfunction and neurodegenerative disease such as Zellweger syndrome [68]. However, an involvement in cardiac function of heart failure has not yet been shown. Also, autoantibodies against HSP70 have been found in this study and HSP70 has been shown to be abundantly expressed in chronically hypoxic heart tissues, indicating a certain role in cardioprotection [69-71].

Although several antigens with a closer connection to heart failure have been identified, the biological role of these antibodies and their corresponding antigens is not clear. It remains to be investigated if the antibodies in plasma identified here cause or have a strong influence on this disease. For example, it has been shown that the extraction of circulating antibodies (subtype IgG3) from the blood of patients with DCM by immunoadsorption has led to an improvement in cardiac function, indicating an active role of these antibodies in the pathogenesis of DCM (Staudt et al. 2002 [12]). However, it cannot be ruled out that some of these circulating antibodies in plasma may be a result of cross-reactivity to other proteins or a secondary product of aberrant pathways or a result of processes such as apoptosis without direct influence on the disease.

Hence, we refer to profiling the antibody repertoire in plasma or serum. The potential of this approach is that it may identify a disease-associated antibody profile which may have the potential to improve the diagnosis of disease, where circulating antibodies play a role, or to potentially improve the subtyping or perhaps even assist in the analysis of the progression or prognosis of such disease. The proteins identified could potentially be candidates for further characterization and validation as potential diagnostic markers. However, for such an application, the proteins identified in this type of analysis would need to be further characterized and functionally and clinically validated and also required to be sufficiently disease-associated to make them relevant for diagnostic applications. A further application of the type of study performed here is that the antigens identified may give insights into the causation of the disease or the mechanism

$$
\begin{array}{lc}
\text { KChIPl } & 737 \text { EEMMDIVKATYDMMGKYT YPVLKEDTPRQHVDVFFQ } 844 \\
\text { Consensus sequence } & \text { +EM+DI+K+ TYDMMGKYTYP L+E + PR+HY+ FFQ } \\
\text { KChIP2 } & 1259 \text { QEMLDTMKSIYDMMGKYTYPALREEAPREHVESFFQ } 1366
\end{array}
$$

Figure 3. Amino acid sequence comparison of KChIP1 and KChIP2. Sequence identity between the KChIP1 and KChIP2 on the amino acid level is over $71 \%$. 
of the progression of such diseases. To improve the power of this approach, larger numbers of well-characterized diseased and control patients would need to be included. Moreover, addition of protein expressing clones derived from a heart cDNA expression library, or by directed subcloning of specific proteins, to the present expression library may lead to improved results.

In general, all of these autoantigens are potential diagnostic markers. Their role and their function for the disease have to be characterized in further projects.

\section{Concluding remarks}

Our results demonstrate that the novel approach of plasma screening on an expression library followed by validation on microarrays is a useful strategy for the identification of putative autoantigens specific for a particular autoimmune disease, in this case DCM. Using this approach we were able to identify 26 autoantigens bound by IgGs and 6 autoantigens specifically bound by the IgG3 subclass. Further steps are now necessary to functionally characterize the identified autoantigens, including plasmon resonance binding affinity studies and in vivo studies in mice.

Such characterized autoantigens are suitable candidates for different diagnostic and therapeutical applications like an "autoimmune DCM chip" or the generation of individual absorption columns for the IA-therapy to remove diseaseassociated autoantibodies in a more specific way.

This work was founded by the Bundesministerium für Bildung und Forschung (BMBF) Grant 0811870 (BioFuture) and the Deutsches Humanes Genomprojekt DHGP 01KW9914 and the Max-Planck-Gesellschaft. This material is based upon works supported by the Science Foundation Ireland under Grant no. 02/CE1/B141. This study was supported in part by the Deutsche Forschungsgemeinschaft (DFG) (LA 1417/1-1-2 and SFB TR 19-04). This work was performed in part fulfilment of the requirements for the Ph.D. of S.H.

\section{References}

[1] Richardson, P. J., Eur. Heart J. 1996, 17, 489-490.

[2] Fu, M., Matsui, S., Keio J. Med. 2002, 51, 208-212.

[3] Keeling, P. J., Goldman, J. H., Slade, A. K., Elliott, P. M. et al., J. Card. Fail. 1995, 1, 337-345.

[4] Liu, P. P., Mason, J. W., Circulation 2001, 104, 1076-1082.

[5] Feldman, A. M., McNamara, D., N. Engl. J. Med. 2000, 343, 1388-1398.

[6] Caforio, A. L., Goldman, J. H., Baig, M. K., Keeling, P. J. et al., Eur. Heart J. 1995, 16, 68-70.

[7] Omerovic, E., Bollano, E., Andersson, B., Kujacic, V. et al., Autoimmunity 2000, 32, 271-280.
[8] Dörffel, W. V., Wallukat, G., Baumann, G., Felix, S. B., Ther. Apher. 2000, 4, 235-238.

[9] Felix, S. B., Staudt, A., Friedrich, G. B., Autoimmunity 2001, $34,211-215$.

[10] Muller, J., Wallukat, G., Dandel, M., Bieda, H. et al., Circulation 2000, 101, 385-391.

[11] Staudt, A., Schaper, F., Stangl, V., Plagemann, A. et al., Circulation 2001, 103, 2681-2686.

[12] Staudt, A., Bohm, M., Knebel, F., Grosse, Y. et al., Circulation 2002, 106, 2448-2453.

[13] Jahns, R., Boivin, V., Hein, L., Triebel, S. et al., J. Clin. Invest. 2004, 113, 1419-1429.

[14] Limas, C. J., Goldenberg, I. F., Limas, C., Circ. Res. 1989, 64, 97-103.

[15] Fu, M. L., Hoebeke, J., Matsui, S., Matoba, M. et al., Clin. Immunol. Immunopathol. 1994, 72, 15-20.

[16] Schulze, K., Becker, B. F., Schauer, R., Schultheiss, H. P., Circulation 1990, 81, 959-969.

[17] Schultheiss, H. P., Kuhl, U., Janda, I., Melzner, B. et al., J. Exp. Med. 1988, 168, 2105-2119.

[18] Liao, Y. H., Cheng, L. X., Dai, S. P., Tu, Y. S., Blood Press. Suppl. 1996, 3, 41-44.

[19] Liao, Y. H., Int. J. Cardiol. 1996, 54, 165-169.

[20] Caforio, A. L., Grazzini, M., Mann, J. M., Keeling, P. J. et al., Circulation 1992, 85, 1734-1742.

[21] Latif, N., Taylor, P. M., Khan, M. A., Yacoub, M. H., Dunn, M. J., Basic Res. Cardiol. 1999, 94, 112-119.

[22] Warraich, R. S., Dunn, M. J., Yacoub, M. H., Biochem. Biophys. Res. Commun. 1999, 259, 255-261.

[23] Felix, S. B., Staudt, A., Landsberger, M., Grosse, Y. et al., J. Am. Coll. Cardiol. 2002, 39, 646-652.

[24] Nishimura, H., Honjo, T., Trends Immunol. 2001, 22, 265268.

[25] Okazaki, T., Tanaka, Y., Nishio, R., Mitsuiye, T. et al., Nat. Med. 2003, 9, 1477-1483.

[26] von Mühlen, C. A., Tan, E. M., Semin. Arthritis Rheum. 1995, 24, 323-358.

[27] Quintana, F. J., Cohen, I. R., Biomed. Pharmacother. 2004, $58,276-281$.

[28] Quintana, F. J., Hagedorn, P. H., Elizur, G., Merbl, Y. et al., Proc. Natl. Acad. Sci. USA 2004, 101 (Suppl 2), 14615-14621.

[29] Brocke, S., Gijbels, K., Allegretta, M., Ferber, I. et al., Nature 1996, 379, 343-346.

[30] Robinson, W. H., Fontoura, P., Lee, B. J., Neuman de Vegvar, H. E. et al., Nat. Biotechnol. 2003, 21, 1033-1039.

[31] Cahill, D., Proteomics: A Trends Guide, Elsevier Science, London 2000, pp. 47-51.

[32] Robinson, W. H., DiGennaro, C., Hueber, W., Haab, B. B. et al., Nat. Med. 2002, 8, 295-301.

[33] Lueking, A., Possling, A., Huber, O., Beveridge, A. et al., Mol. Cell Proteomics 2003, 2, 1342-1349.

[34] Büssow, K., Cahill, D., Nietfeld, W., Bancroft, D. et al., Nucleic Acids Res. 1998, 26, 5007-5008.

[35] Lehrach, H., Bancroft, D., Maier, E., Interdisciplinary Sci. Rev. 1997, 22, 37-44.

[36] Büssow, K., Nordhoff, E., Lübbert, C., Lehrach, H., Walter, G., Genomics 2000, 65, 1-8. 
[37] Schmidt, F., Lueking, A., Nordhoff, E., Gobom, J. et al., Electrophoresis 2002, 23, 621-625.

[38] Altschul, S. F., Madden, T. L., Schaffer, A. A., Zhang, J. et al., Nucleic Acids Res. 1997, 25, 3389-3402.

[39] Lueking, A., Horn, M., Eickhoff, H., Büssow, K. et al., Anal. Biochem. 1999, 270, 103-111.

[40] Robinson, W. H., Steinman, L., Utz, P. J., Arthritis Rheum. 2002, 46, 885-893.

[41] Brizuela, L., Richardson, A., Marsischky, G., Labaer, J., Arch. Med. Res. 2002, 33, 318-324.

[42] Braun, P., Hu, Y., Shen, B., Halleck, A. et al., Proc. Natl. Acad. Sci. USA 2002, 99, 2654-2659.

[43] Lacroix-Desmazes, S., Kaveri, S. V., Mouthon, L., Ayouba, A. et al., J. Immunol. Methods 1998, 216, 117-137.

[44] Lacroix-Desmazes, S., Moreau, A., Pashov, A., Sooryanarayana et al., Semin. Thromb. Hemost. 2000, 26, 157-165.

[45] Pashov, A., Kenderov, A., Kyurkchiev, S., Kehayov, I. et al., Int. Immunol. 2002, 14, 453-461.

[46] Cahill, D. J., Nordhoff, E., Adv. Biochem. Eng. Biotechnol. 2003, 83, 177-187.

[47] Huels, C., Muellner, S., Meyer, H. E., Cahill, D. J., Drug Discov. Today 2002, 7, S119-S124.

[48] McCarthy, J. J., Meyer, J., Moliterno, D. J., Newby, L. K. et al., Hum. Genet. 2003, 114, 87-98.

[49] Gonzalez, P., Alvarez, R., Reguero, J. R., Batalla, A. et al., Coron. Artery Dis. 2002, 13, 251-254.

[50] Qu, X., Zhang, C., Zhai, Y., Xing, G. et al., Gene 2001, 264, 3744.

[51] Helin, K., Lees, J. A., Vidal, M., Dyson, N. et al., Cell 1992, 70, 337-350.

[52] Sansal, I., Dupont, E., Toru, D., Evrard, C., Rouget, P., Oncogene 2000, 19, 5000-5009.

[53] Swanton, E. M., Saggerson, E. D., Biochim. Biophys. Acta $1997,1346,93-102$.
[54] Yu, C. H., Panagia, V., Tappia, P. S., Liu, S. Y. et al., Biochim. Biophys. Acta 2002, 1584, 65-72.

[55] Puceat, M., Vassort, G., Mol. Cell. Biochem. 1996, 157, 65-72.

[56] Schwinger, R. H., Hoischen, S., Reuter, H., Hullin, R., J. Mol. Cell. Cardiol. 1999, 31, 283-296.

[57] Asahi, M., Otsu, K., Nakayama, H., Hikoso, S. et al., Proc. Natl. Acad. Sci. USA 2004, 101, 9199-9204.

[58] Cheng, C. F., Kuo, H. C., Chien, K. R., Trends Mol. Med. 2003, 9, 59-66.

[59] Kuo, H. C., Cheng, C. F., Clark, R. B., Lin, J. J. et al., Cell 2001, 107, 801-813.

[60] Nogales, E., Downing, K. H., Amos, L. A., Lowe, J., Nat. Struct. Biol. 1998, 5, 451-458.

[61] Adyel, F. Z., Hentati, B., Boulila, A., Hachicha, J. et al., J. Clin. Lab. Anal. 1996, 10, 451-457.

[62] Bernier-Valentin, F., Rabilloud, R., Rousset, B., Clin. Exp. Immunol. 1988, 71, 261-268.

[63] Zhou, R. H., Kokame, K., Tsukamoto, Y., Yutani, C. et al., Genomics 2001, 73, 86-97.

[64] Nishimoto, S., Tawara, J., Toyoda, H., Kitamura, K. et al., Eur. J. Biochem. 2003, 270, 2521-2531.

[65] Liu, J., Farmer, J. D., Jr., Lane, W. S., Friedman, J. et al., Cell 1991, 66, 807-815.

[66] Dubois, S., Shou, W., Haneline, L. S., Fleischer, S. et al., Proc. Natl. Acad. Sci. USA 2003, 100, 14169-14174.

[67] Varela-Calvino, R., Sgarbi, G., Wedderburn, L. R., Dayan, C. M. et al., J. Immunol. 2001, 167, 3513-3520.

[68] Lazarow, P. B., J. Neuropathol. Exp. Neurol. 1995, 54, 720725.

[69] Marber, M. S., Mestril, R., Chi, S. H., Sayen, M. R. et al., J. Clin. Invest. 1995, 95, 1446-1456.

[70] Hutter, J. J., Mestril, R., Tam, E. K., Sievers, R. E. et al., Circulation 1996, 94, 1408-1411.

[71] Trost, S. U., Omens, J. H., Karlon, W. J., Meyer, M. et al., J. Clin. Invest. 1998, 101, 855-862. 